\title{
PELATIHAN PENGELASAN 1G, GUNA MENINGKATKAN PENDAPATAN DAN KEMAMPUAN ANDIKPAS PASCA BEBAS DARI LEMBAGA PEMASYARAKATAN KHUSUS ANAK TOMOHON
}

\section{Training for $1 G$ Welding, To Increase Income and Skill of Andikpas for free of Tomohon Child Special Prison Institution}

\author{
Moh. Fikri Pomalingo ${ }^{1)}$, Muh. Muhdi Attaufiq ${ }^{2)}$, Hendro M.Sumual ${ }^{3)}$, Bastian Rikardo Parhusip ${ }^{3)}$, \\ I Wayan Gede Suarjana ${ }^{4)}$ \\ 1, Program Studi Teknik Mesin, ${ }^{2,}$ Program Arsitektur, ${ }^{3,}$ Jurusan Pendidikan Teknik Mesin, \\ 4, Program Studi Ilmu Kesehatan Masyarakat \\ Universitas Negeri Manado \\ Email: fikripomalingo@unima.ac.id ${ }^{1)}$
}

\begin{abstract}
ABSTRAK
Dalam peradilan pidana anak di Indonesia, pemerintah mendirikan lembaga khusus yang bertugas untuk menangani hal tersebut. Lembaga tersebut dikenal dengan istilah LPKA dan LPAS. Hasil diskusi tim bersama ketua LPKA Tomohon, diperoleh informasi bahwa, masih kurang pembinaan terkait peningkatan kemampuan anak. Salah satu peningkatan tersebut, terkait pelatihan pengelasan. Disisi lain, pihak LPKA telah menyediakan fasilitas ruangan dan berencana untuk membangun workshop pengelasan, namun terkendala biaya, sehingga belum direalisasikan. Tim pengabdi UNIMA melalui Program Kemitraan Masyarakat telah merealisasikan pelatihan pengelasan tersebut. Tujuan penulisan artikel ini adalah untuk memberikan pelatihan pengelasan, mengevaluasi dan melaporkan hasil pelatihan yang telah dilaksanakan terkait pengelasan 1G. Metode yang diterapkan meliputi pembuatan workshop pengelasan, pemberian teori terkait pengelasan, penggunaan mesin, pengukuran, pemotongan bahan, dan pengecatan, serta pemberian praktek dan pembuatan tugas. Kegiatan teori dilakukan selama 6 hari dan praktek selama 21 hari. Jenis pengelasan yang dilatihkan adalah. Hasil yang diperoleh, semua peserta yang berjumlah 20 orang, mampu melakukan pelatihan dengan baik. Hal itu ditunjukkan dengan hasil presentasi yang berada diatas $70 \%$. Pelatihan ini juga, memberikan hasil produk yang baik. Kegiatan ini dilakukan pada masa pandemi covid 19, namun semua peserta dan tim melaksanakan kegiatan dengan menaati protokol kesehatan yang ketat.
\end{abstract}

Kata kunci: LPKA, Andikpas, 1G, Pengelasan, Tomohon

\section{ABSTRACT}

In juvenile criminal justice in Indonesia, the government established a special institution tasked with dealing with this matter. These institutions are known as LPKA and LPAS. The results of the team discussion with the head of LPKA Tomohon, information was obtained that, there was still a lack of guidance related to improving children's abilities. One of these improvements is related to welding training. On the other hand, the LPKA has provided room facilities and plans to build a welding workshop, but the cost is constrained, so it has not been realized. The Unima service team through the Community Partnership Program has realized the welding 
training. The purpose of writing this article was to provide welding training, evaluate and report the results of the training that has been carried out related to $1 G$ welding. The methods applied include making welding workshops, giving theories related to welding, using machines, measuring, cutting materials, and painting, as well as giving practice and making assignments. Theoretical activities were carried out for 6 days and practical activities for 21 days. The type of welding being trained is. The results obtained, all the participants, totaling 20 people, were able to carry out the training well. This is indicated by the results of the presentation which is above $70 \%$. This training, too, provides good product results. This activity was carried out during the COVID-19 pandemic, but all participants and teams carried out activities by adhering to strict health protocols.

\section{Keywords: lpka, andikpas, 1g, pengelasan, tomohoan}

\section{PENDAHULUAN}

Dalam peradilan pidana anak di Indonesia, pemerintah mendirikan lembaga khusus yang bertugas untuk menangani hal tersebut. Lembaga tersebut dikenal dengan istilah LPKA dan LPAS. Lembaga pemasyarakatan atau disingkat LP atau Lapas adalah tempat untuk melakukan pembinaan terhadap narapidana dan anak didik pemasyarakatan di Indonesia (Arianto, 2016). LPKA merupakan singkatan dari Lembaga Pembinaan Khusus Anak, sedangkan LPAS merupakan Lembaga Penempatan Anak Sementara. Kedua lembaga ini berada dibawah naungan Direktorat Jendral Pemasyarakatan Kementrian Hukum dan HAM Republik Indonesia. Kedua Lembaga itu juga merupakan salah satu perwujudan bangsa dalam pemenuhan hak dan dan perlindungan anak, agar anak yang berkonflik dengan hukum tetap dapat tumbuh dan berkembang secara optimal.

Tahun 2015 walikota Tomohon Jimmy F. Eman SE. Ak meresmikan LPKA dan LPAS kelas II Tomohon. Berdasarkan sejarahnya LPKA ini didirikan pada tahun 1981 diatas tanah seluas $59.641 \mathrm{~m}^{2}$ dengan luas bangunan $39.646 \mathrm{~m}^{2}$. Bangunan LPKA Tomohon memiliki suasana yang asri serta dikelilingi pagar tembok setinggi $4 \mathrm{~m}$. Bangunan LPKA Tomohon terdiri dua bangunan utama. Bangunan pertama adalah perkantoran dan penjara yang memiliki atap berwarna merah, sedangkan bangunan utama kedua adalah sarana keterampilan, dapur, aula, kelas, dan tempat ibadah.

Tujuan lain dari pembinaan di LPKA yaitu untuk kontrol sosial WBP (Warga Binaan Pemasyarakatan) agar kembali patuh terhadap norma-norma yang ada di masyarakat (Banurea, 2019). Dalam peningkatan pelayanan pendidikan, keterampilan serta minat dan bakat WBP, Pihak LPKA telah menjalin kerjasama dengan beberapa instansi. 1) untuk pelayanan pendidikan, LPKA bekerjasama dengan pemerintah kota Tomohon dalam hal ini dinas pendidikan melalui fasilitas pendidikan paket $\mathrm{A}, \mathrm{B}$, dan $\mathrm{C}, 2$ ) untuk meningkatkan wawasan dalam membaca, LPKA bekerjasama dengan dinas perpustakaan kota tomohon melalui bantuan buku dan perpustakaan keliling, 3) untuk pembinaan mental dan nasionalisme, LPKA dibantu oleh organisasi kepramukaan, 4) peningkatan bidang kesenian menyanyi LPKA bekerja sama dengan Pertamina Geothermal Lahendong dan TVRI, dan 5) dan untuk keterampilan seni rupa, LPKA bekerja sama dengan industri kerajinan kayu setempat.

Hasil penelusuran artikel yang dilakukan, belum ada yang melaporkan 
kegiatan penelitian dan pengabdian terkait pelatihan pengelasan bagi andikpas. Kegiatan hanya sebatas dilakukan oleh perusahaan atau mitra tanpa dilaporkan dalam bentuk jurnal. Pada umumnya hanya melaporkan pada kegiatan psikologi. Ariyanto (2016) melakukan penelitian terkait tingkat stress pada lapas anak di Blitar. Utami dan Asih (2016) melaporkan kegiatan pada LPKA hanya terkait rasa bersalah dan konsep diri.

Banyaknya fasilitas ruangan yang ada di LPKA Tomohon, membuat kepala lapas (kalapas) berencana untuk membuat bengkel las. Hal ini dimaksudkan untuk membekali andikpas (anak didik lapas) dengan keterampilan pengelasan. Alasan ini yang menjadi acuan penulis membuat Program Kemitraan Masyarakat (PKM) dan menjalin kerjasama antara tim pengabdi dari Universitas Negeri Manado (unima), dengan LPKA Tomohon. PKM ini didanai oleh KEMENDIKBUD RISTEK, dengan harapan melatih andikpas teknik pengelasan dasar, agar nantinya dapat digunakan pasca bebas dari LPKA Tomohon.

Pelatihan pengelasan dilaksanakan pada masa pandemi covid 19. Semua peserta diwajibkan mematuhi protokol kesehatan. Pada pelatihan ini juga, peserta wajib menggunakan Alat Pelindung Diri (APD) yang standar digunakan di bengkel. APD itu meliputi sarung tangan, sepatu safety, kacamata kerja, baju kerja, dan pelindung telinga. Untuk mematuhi protokol kesehatan, maka semua peserta dan tim pengabdi menggunakan masker dan mematuhi protokol kesehatan covid 19 lainnya.

\section{PERMASALAHAN DAN SOLUSI Permasalahan}

Hasil diskusi antara tim PKM Unima dan mitra, serta pengamatan langsung di LPKA. Terdapat beberapa permasalahan prioritas yang disepakati untuk diselesaikan bersama melalui program PKM. Permasalahannya yaitu;
1. Belum adanya bengkel las untuk pelatihan,

2. Pada dasarnya peserta juga belum mengetahui pengelasan $1 \mathrm{G}$.

3. Mitra belum pernah menggunakan mesin las dan membuat produk dari proses pengelasan.

\section{Solusi}

Dalam peningkatan kualitas pelatihan di LPKA tomohon, kepala LPKA memberikan fasilitas berupa ruangan dan mesin las 2 unit. Fasilitas ini merupakan join pendanaan dari KEMENDIKBUD RISTEK. Solusi yang dilakukan dari pelatihan ini adalah:

1. Pemberian alat las dan membuat bengkel las di LPKA Tomohon

2. Memberikan pelatihan pengelasan $1 \mathrm{G}$

3. Pemberian pelatihan K3.

4. Melakukan pembuatan produk pengelasan.

\section{METODE PELAKSANAAN}

Pelaksanaan program pelatihan pengelasan dilakukan selama 1 bulan bertempat di Workshop Ketapel LPKA Tomohon. Peserta yang dilibatkan sebanyak 20 orang. 16 orang merupakan andikpas dan 4 orang adalah pegawai lapas. Andikpas yang diikutkan adalah yang akan bebas, dengan durasi bebas paling lama 6 bulan pasca pelatihan. Tujuan keterlibatan pegawai, untuk meneruskan proses pelatihan nanti pasca kegiatan ini berakhir.

Kegiatan pelatihan dibagi dalam dua kategori yakni teori dan praktek. Teori dilakukan selama satu pekan yakni 3-9 Mei 2021, sedangkan praktek dilakukan selama tiga pekan yakni 2-20 Juni 2021. Adapun uraian kegiatan dibagi dua tahap.

Teori dilaksanakan dengan metode ceramah. Kegiatan penyampaian materi meliputi pengelasan $1 \mathrm{G}, \mathrm{K} 3$, pengecatan, dan pembuatan produk. Materi pengelasan disampaikan oleh ketua tim. Materi K3 disampaikan oleh tim. Upaya keselamatan 
dan kesehatan kerja merupakan salah satu aspek perlindungan tenaga kerja untuk mencapai produktivitas kerja yang optimal (Permatasari, et. al. 2017).

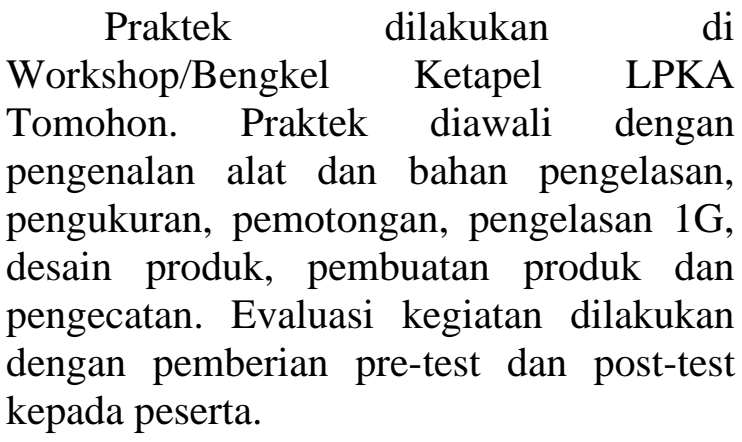

\section{HASIL DAN PEMBAHASAN}

\section{Pelaksanaan Kegiatan}

Pelatihan pengelasan untuk Andikpas merupakan hal baru yang dilakukan. Pada umumnya kegiatan yang dilaksanakan hanya meliputi pelatihan pembuatan pernakpernik, pembuatan minyak kelapa, pembuatan tahu, dan lain sebagainya. Belum adanya pelatihan pengelasan, diduga karena peralatan yang relatif mahal serta akan mengalami resiko kecelakaan kerja. Pelaksanaan kegiatan pelatihan pengelasan dan pembuatan produk dalam kegiatan ini, mengacu pada metode pelaksanaan kegiatan yang sudah dirancang oleh tim (Harimurti, 2018), sebelum dilakukan pelatihan, terlebih dahulu diambil data awal (pretest) pengetahuan kognitif dan psikomotorik Andikpas tentang pengelasan SMAW. dari data yang kami dapatkan 96\% Andikpas tidak mengetahui cara menggunakan mesin las dan bahkan dari hasil wawancara yang kami lakukan secara personal, 16 orang dari Andikpas belum pernah melihat dan memegang mesin las secara langsung. dari data awal yang kami dapatkan maka di minggu pertama tim fokus untuk memberikan materi-materi yang dibutuhkan saat praktek pengelasan.

Setelah semua materi selesai diberikan tim memberikan pelatihan pengelasan di minggu ke 2. Sebelum pelatihan pengelasan diberikan terlebih dahulu Andikpas dibekali dengan pengenalan alat beserta fungsinya, dimaksudkan supaya Andikpas lebih paham dan mengerti cara menggunakan peralatan-peralatan yang ada di bengkel pengelasan. Setelah pembekalan tentang peralatan selesai maka Andikpas diberikan arahan untuk selalu menggunakan APD, tim memberikan Wearpack, Kacamata, sarung tangan, dan Sepatu safety untuk masing-masing Andikpas. Hasil pengamatan di lapangan, semua peserta kegiatan pelatihan menggunakan APD secara lengkap. Rincian kegiatan pelatihan dilakukan seperti berikut:

\section{Pengelasan 1G}

Pelatihan pengelasan awal yang diberikan adalah pengelasan datar di bawah tangan (1G). Pelatihan awal menggunakan besi plat tebal $2 \mathrm{~mm}$. Pada pelatihan ini peserta sengaja diberi benda kerja yang tipis supaya terlatih mengatur tegangan mesin, menambal benda kerja yang bolong dan memilih jenis kawat las. Dokumentasi pelatihan pengelasan $1 \mathrm{G}$ dapat dilihat pada Gambar 1 dan 2.

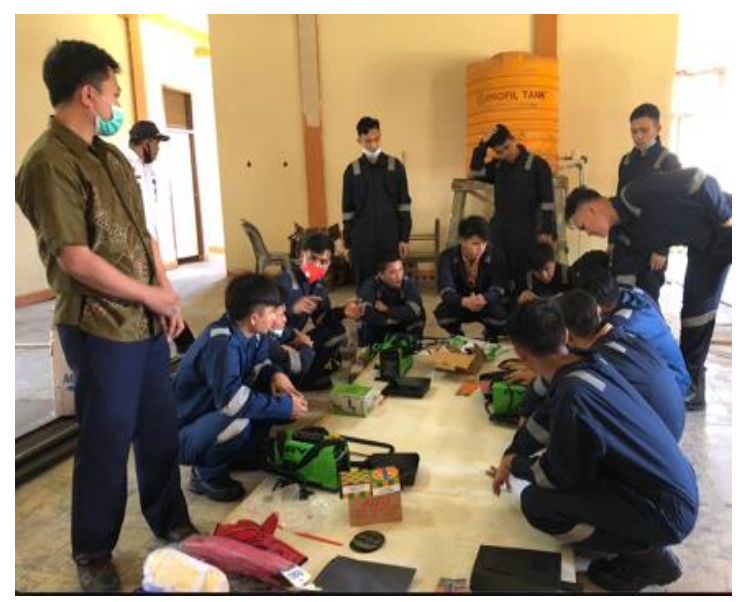

Gambar 1. Pengenalan Alat dan Fungsinya 


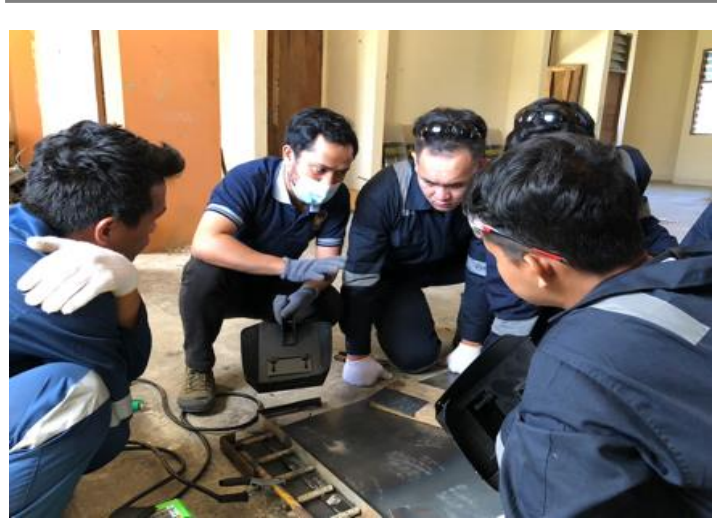

Gambar 2. Pelatihan Pengelasan 1G

Pelatihan pengelasan awal menggunakan plat tipis. Hal itu memang sangat sulit untuk pemula, tetapi itu merupakan strategi yang dilakukan oleh tim, supaya peserta terlatih untuk mengelas benda kerja yang tipis. Peserta terlatih untuk mengatur tegangan mesin las pada

benda kerja tipis dan tebal, dan peserta terlatih untuk memperbaiki benda kerja yang rusak saat pengelasan. Pada saat pelatihan pengelasan di plat tipis, benda kerja semua peserta bocor dan mereka bisa memperbaiki dengan cara menambal benda kerja dengan kawat las. Pelatihan awal menggunakan benda kerja Plat tebal $2 \mathrm{~mm}$ membutuhkan waktu 24 jam pertemuan atau setara 3 hari $(1$ hari $=8$ jam $)$.

Peserta juga membuat satu produk sambil mengaplikasikan apa yang sudah mereka latih di pertemuan pengelasan plat tipis seperti pada Gambar 3.

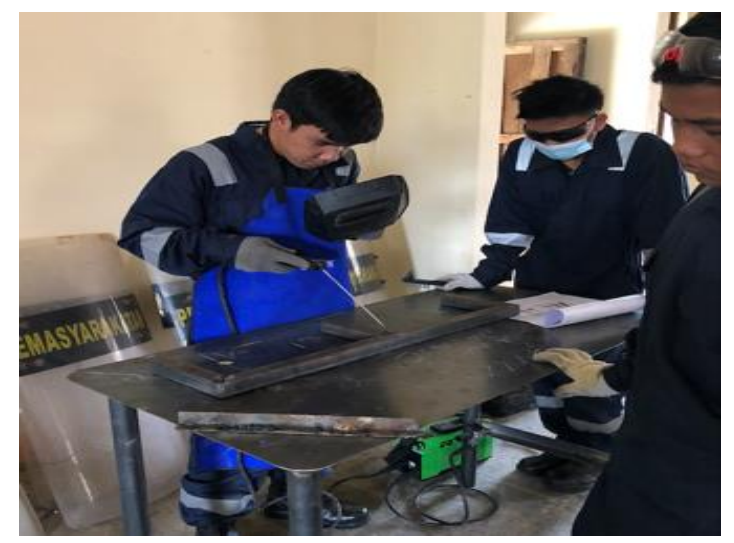

Gambar 3. Peserta Melakukan Pengelasan $1 \mathrm{G}$
Beberapa hasil pengelasan $1 \mathrm{G}$ peserta dapat dilihat dalam Gambar 4. Hasil ini terlihat bagus dan kuat. Sambungan hasil pengelasan dari las listrik dapat bertahan lama dan kuat (Fahrudin, 2018).

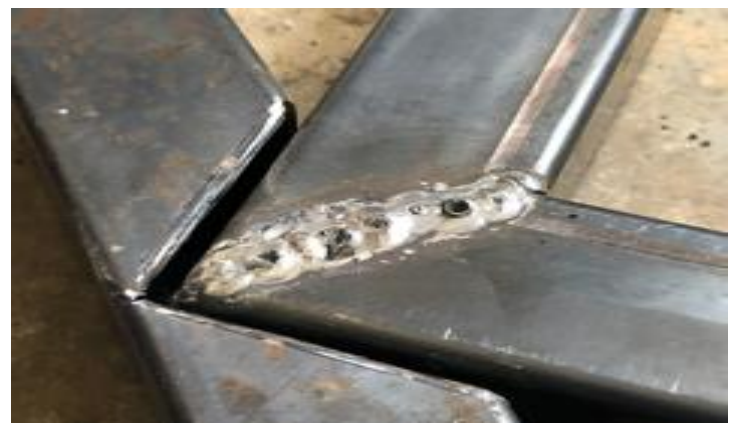

Gambar 4. Hasil Pengelasan

Dari hasil evaluasi dan monitoring yang dilakukan tim maka dapat disimpulkan bahwa $70 \%$ peserta sudah bisa menggunakan mesin las dan mengelas rata dengan kategori baik, 20\% sangat baik dan $10 \%$ cukup baik, seperti yang terlihat dalam diagram persentase nilai pada Gambar 5.

\section{Pengelasan 1G}

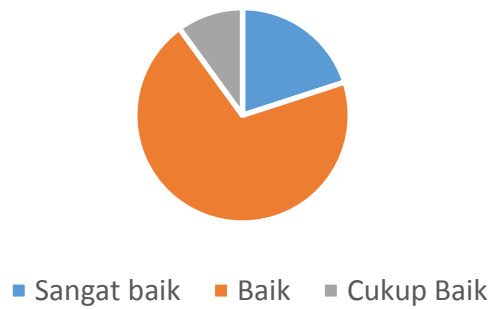

Gambar 5. Diagram perolehan Nilai peserta pengelasan $1 \mathrm{G}$

\section{Keaktifan Peserta Pelatihan}

Selama kegiatan berlangsung tim selalu memperhatikan antusiasme dan keaktifan peserta pada saat pelatihan berlangsung. Hal ini sebagai acuan untuk melakukan pengembangan pelatihan atau acuan untuk mencapai tujuan dari pelatihan. Keberhasilan dalam pencapaian tujuan dari pelatihan ini tidak boleh dilepaskan dari kedisiplinan dan keaktifan peserta pada saat kegiatan berlangsung (Permatasari et. al. 
2016). Adapun indikator yang digunakan untuk mengukur keaktifan peserta pada saat pelatihan adalah sebagai berikut:

a) Kesiapan peserta selama mengikuti pelatihan dengan menggunakan alat pelindung diri. APD yang dimaksud berupa Wearpack, Sepatu safety, sarung tangan, kacamata safety dan kacamata las. Pada saat pelatihan, peserta berjumlah 20 orang dengan kata lain $100 \%$. Peserta menggunakan APD selama pelatihan berlangsung. Gambar 6 menunjukkan peserta yang menggunakan APD lengkap beserta masker.

b) Peserta mengikuti pelatihan dengan antusias dan disiplin. Pada minggu 1 para peserta yang antusias dan disiplin saat mengikuti kegiatan berjumlah 19 orang $(95 \%)$. Hal ini menunjukkan bahwa peserta mengikuti pelatihan dengan antusias dan disiplin masuk dalam kategori sangat aktif. Pada pertemuan minggu ke-2, observasi terhadap disiplin dan antusias peserta saat kegiatan berlangsung tetap dilakukan dan dari hasil observasi 20 orang $(100 \%)$. Peserta mengikuti kegiatan dengan sangat disiplin dan antusias, dengan demikian di minggu ke 2 disiplin dan antusiasme peserta saat mengikuti kegiatan masuk dalam kategori sangat aktif. Pada minggu ke-3 para peserta yang antusias dan disiplin saat mengikuti kegiatan berjumlah 18 orang $(90 \%)$. Hal ini menunjukkan bahwa peserta mengikuti pelatihan dengan antusias dan disiplin masuk dalam kategori sangat aktif. Pada minggu ke 4 para peserta yang antusias dan disiplin saat mengikuti kegiatan berjumlah 20 orang $(100 \%)$ hal ini menunjukkan bahwa peserta mengikuti pelatihan dengan antusias dan disiplin masuk dalam kategori sangat aktif. Hal ini menunjukkan bahwa secara keseluruhan peserta mengikuti pelatihan dengan antusias dan disiplin masuk dalam kategori sangat aktif.

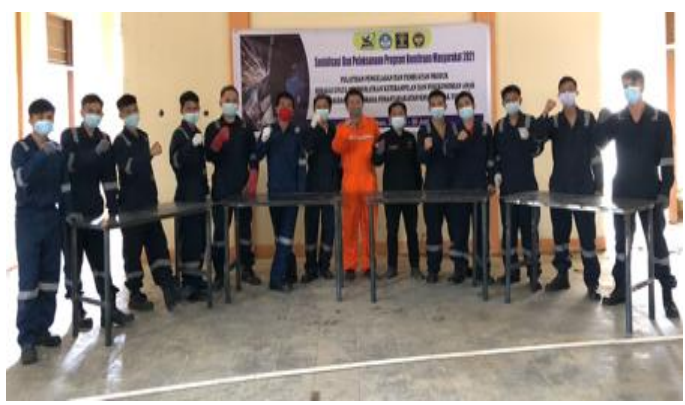

Gambar 6. Kesiapan Peserta Mengikuti Pelatihan

c) Peserta yang ambil bagian dalam menyelesaikan proyek kelompok secara konsisten pada minggu 1 berjumlah 8 orang. (40\%) masuk dalam kategori cukup aktif karena rendahnya kemauan peserta untuk ambil bagian dalam penyelesaian proyek kelompok. Tim memberikan pekerjaan khusus bagi masing-masing anggota kelompok supaya pekerjaan berbagi rata dan tidak ada anggota kelompok yang terbebani oleh satu pekerjaan. Pada minggu ke-2, terlihat ada peningkatan signifikan peserta yang ambil bagian dalam menyelesaikan proyek yaitu 16 orang (80\%) masuk dalam kategori aktif. Minggu ke-3 berlangsungnya kegiatan terlihat adanya peningkatan peserta yang ambil bagian dalam menyelesaikan proyek yaitu 20 orang $(100 \%)$ dikarenakan tim memberikan satu proyek bagi masing-masing kelompok untuk dikerjakan dan kelompok yang selesai duluan akan mendapatkan nilai baik dari tim. Hal ini menunjukkan bahwa di minggu ke 3 Peserta yang ambil bagian dalam menyelesaikan proyek kelompok masuk dalam kategori sangat aktif. Pada minggu ke-4 Peserta yang ambil bagian dalam menyelesaikan proyek kelompok berjumlah 20 orang (100\%) dan masuk dalam kategori sangat aktif. Dapat disimpulkan bahwa Peserta yang ambil 
bagian dalam menyelesaikan proyek kelompok selama kegiatan berlangsung adalah Sangat Aktif seperti terlihat pada Gambar 7.

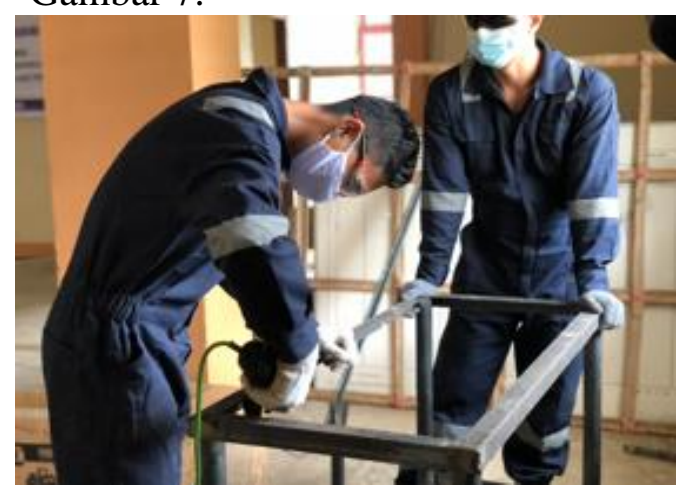

Gambar 7. Penyelesaian Proyek kelompok

\section{KESIMPULAN DAN SARAN \\ Kesimpulan}

Dari pembahasan dan analisis yang telah dilakukan, dapat disimpulkan bahwa;

1. Peserta mampu menguasai teknik pengelasan $1 \mathrm{G}$ dengan baik, hal itu dibuktikan dengan hasil penilaian dan produk yang dihasilkan.

2. Pembagian tugas secara berkelompok mampu memberikan kerjasama yang baik khususnya dalam penanganan tugas masing-masing peserta.

3. Kendala mata, masih menjadi hal yang umum dirasakan oleh peserta, utamanya yang baru pertama kali mengelas. Dan masih terdapat peserta yang takut melakukan pengelasan dan pemotongan bahan dengan menggunakan gerinda. Hal ini dikarenakan trauma pernah melihat kecelakaan kerja saat dibengkel.

\section{Saran}

Kegiatan pelatihan untuk Andikpas sangat bermanfaat, oleh karena itu, setiap LPKA sebaiknya memikirkan hal yang serupa, demi meningkatkan skill andikpas, dan memberikan keadilan dalam hal pendidikan utamanya bagi masyarakat yang menjalani hukuman. Pelatihan lain dapat berupa pengelasan, kelistrikan, handicraft dan lain sebagainya.

\section{UCAPAN TERIMA KASIH}

Terimakasih tim ucapkan kepada Kementerian Pendidikan, Kebudayaan, Riset dan Teknologi yang telah mendanai seluruh program ini. Program ini merupakan Program Kemitraan Masyarakat dari skim Pengabdian Kepada Masyarakat SIMLITABMAS.

\section{DAFTAR PUSTAKA}

Arianto, E.A. 2016. Tingkat Stress Anak Remaja di Lapas Anak Blitar. Jurnal Psikologi Indonesia. Vol. 5. No. 3. Hal. 226-231.

Banurea, R.N. 2019. Wajah Humanis Penjara: Pembinaan Pelaku Perkosaan di Lembaga Pemasyarakatan Kelas II A Abepura. Jurnal Pemberdayaan Masyarakat Papua (JPMP).Vol. 1 No. 1. 2019. ISSN. 2657-1943.

Fahrudin, A. 2018. Perencanaan Sambungan Las Pada Konstruksi Rangka Mesin Disc Mill Tinja Kambing Manual sebagai Bahan Pupuk Organik. Jurnal Mahasiswa Teknik Mesin ITN. Vol. 01. No. 1. Tahun 2018. Hal 7-12.

Harimurti, E.R. 2018. Evaluasi Pelaksanaan Program Pendidikan Pusat Kegiatan Belajar Masyarakat (PKBM) LAPAS Kelas IIA Salemba Dalam Rangka Pemenuhan Hak Anak Didik Pemasyarakatan. Journal of Economics and Social Research UNES. Vol. 3. No. 2. ISSN 2528-6218.

Masu, R.R., Aloysius, S. 2016. Model Pemberdayaan Hakim Pengawas dan Pengamat Berbasis Koordinasi dalam Mewujudkan Pengarusutamaan Hak Anak (PUHA) di Lapas Anak Kelas IIA Kupang / Lembaga Pembinaan Khusus Anak Kupang (LPKA). Jurnal Hukum Universitas Negeri Nusa Cendana. Hal. 224-238.

Pattiasina, N.H., Holle, S., Keppy, I.H. 2018. Pelatihan Proses Pengelasan Menggunakan Mesin Las Listrik dalam 
Upaya Peningkatan Keterampilan Pekerja di Desa Rumahtiga. Jurnal Simetrik. Vol. 8, No. 1. Juni 2018. ISSN: 2302-9579. Hal. 77-83.

Permatasari, G., Setiadi, G., Arifin. 2017. Hubungan Pengetahuan, Sikap dan Kenyamanan Pekerja dengan Pemakaian Alat Pelindung Diri (APD) di Bengkel Las Listrik Kecamatan Amuntai Tengah Kabupaten HSU Tahun 2016. Jurnal Kesehatan Lingkungan Vol 14, No. 1. Januari 2017. Hal. 383-390.

Utami, R.R., Asih, M.K. 2016. Konsep Diri dan Rasa Bersalah pada Anak Didik Lembaga Pemasyarakatan Anak Kelas IIA Kutoarjo. Jurnal IndigenousVol. 1 No. 1 Mei 2016. ISSN: 0854-2880. 84-91 